\title{
Combined small cell carcinoma with giant cell carcinoma component of the lung: A case successfully diagnosed by computed tomography-guided fine-needle aspiration cytology
}

\author{
YUSUKE EBISU $^{1}$, MITSUAKI ISHIDA ${ }^{1}$, TOMOHITO SAITO ${ }^{2}$, TOMOHIRO MURAKAWA ${ }^{2}$, \\ YOSHIKO UEMURA $^{1}$ and KOJI TSUTA ${ }^{1}$ \\ Departments of ${ }^{1}$ Pathology and Laboratory Medicine and ${ }^{2}$ Thoracic Surgery, \\ Kansai Medical University, Osaka 573-1010, Japan
}

Received July 3, 2017; Accepted November 6, 2017

DOI: $10.3892 / 01.2017 .7448$

\begin{abstract}
Combined small cell lung carcinoma (SCLC) is a rare variant of SCLC and is defined as a mixture of SCLC and non-SCLC components. Although any histopathological subtype may be present as a non-SCLC component, the presence of pleomorphic carcinoma components are extremely rare. The present report describes the first documented cytological features of combined SCLC with a giant cell carcinoma component. A 50-year-old Japanese female with a history of smoking presented with a mass lesion in the left lung. Computed tomography-guided fine-needle aspiration cytology and needle biopsy were performed, followed by a lobectomy. A Papanicolaou smear revealed the presence of two distinct neoplastic components in a necrotic background. One component was SCLC, which comprised small-sized neoplastic cells containing scant cytoplasm and round to oval nuclei with dispersed granular chromatin without nucleoli. The other component was giant cell carcinoma, which was composed of large-sized neoplastic cells containing irregular large hyperchromatic nuclei (approximately 7 to 10 times larger than those of SCLC). SCLC was demonstrated in the biopsy specimen, however no giant cell carcinoma component was present. Histopathological study of the lobectomy specimen verified a diagnosis of combined SCLC with giant cell carcinoma component. Both SCLC and giant cell carcinoma exhibit characteristic cytological features, therefore, albeit extremely rare, careful observation may lead to a correct diagnosis of combined SCLC in the cytological specimen.
\end{abstract}

Correspondence to: Mr. Yusuke Ebisu, Department of Pathology and Laboratory Medicine, Kansai Medical University, 2-5-1 Shinmachi, Hirakata, Osaka 573-1010, Japan

E-mail: ebisuyu@hirakata.kmu.ac.jp

Key words: combined small cell carcinoma, giant cell carcinoma, lung

\section{Introduction}

Combined small cell lung carcinoma (SCLC) is categorized as a histopathological variant of SCLC, and defined as an admixture of SCLC and non-SCLC components (1). The incidence of combined SCLC is $0.2 \%-1.3 \%$ of the surgically resected primary lung cancers $(2,3)$, and comprises up to $28 \%$ of the surgically resected SCLC cases (4). Adenocarcinoma and squamous cell carcinoma are the common components of non-SCLC (2-5). In the case series reported by Yamada et al adenocarcinoma is the most common histopathological subtype of the non-SCLC component (6/9 cases), followed by adenocarcinoma and squamous cell carcinoma ( 2 cases) and squamous cell carcinoma (1 case) (2). Any histopathological subtypes can be present as a non-SCLC component (1). However, the occurrence of a pleomorphic (giant cell) carcinoma component in combined SCLC is extremely rare (6-9). We have already reported on the clinical and histological characteristics of this case (10), and this report we described the detailed cytological features of combined SCLC with giant cell carcinoma component in order to draw attention to a potential cause of diagnostic error.

\section{Case report}

A 50-year-old Japanese female was referred to Kansai Medical University Hospital because of an abnormal chest shadow, which had been detected by a chest X-ray examination at an out-patient clinic. She was a heavy smoker (30 cigarettes daily over 30 years). Chest computed tomography (CT) demonstrated a relatively well-circumscribed mass lesion, measuring $23.8 \times 20.8 \mathrm{~mm}$ in diameter, in S6 of the left lung. Her serum tumor markers were elevated [neuron specific enolase, $21.0 \mathrm{ng} / \mathrm{ml}$ (range, <12) and ProGRP, $84.4 \mathrm{pg} / \mathrm{ml}$ (range, <46)].

CT-guided fine-needle aspiration cytology examination and needle biopsy were performed for this lesion. Bronchoscpoic biopsy was not performed due to the location of the tumor. Subsequently, lobectomy of the left lower lobe and lymph node dissection were performed.

The post-operative course was uneventful, and no tumor recurrence has been observed during 13 months of medical follow-up. 
The CT-guided fine-needle aspiration cytology specimens were stained conventionally with Papanicolaou stain.

Formalin-fixed and paraffin-embedded CT-guided needle biopsy and surgically resected specimens of the lung were processed for routine histological examination and immunohistochemical analyses.

In this report, immunohistochemical analyses were performed using an autostainer (XT System Benchmark; Roche Diagnostics, Basel, Switzerland; or Autostainer link 48; DakoCytomation, Glostrup, Denmark) according to the manufacturer's instructions. The primary antibodies used in this report were a mouse monoclonal antibody against chromogranin A (LK2H10; Cell Marque, Rocklin, CA, USA), a mouse monoclonal antibody against CD56 (123c3; DakoCytomation), a mouse monoclonal antibody against E-cadherin (NCH-38; DakoCytomation), a mouse monoclonal antibody against $\mathrm{p} 40$ (BC28; Novocastra Laboratories, Ltd., Newcastle upon Tyne, UK), a mouse monoclonal antibody against synaptophysin (27G12; Nichirei Bioscience, Tokyo, Japan), a mouse monoclonal antibody against thyroid transcription factor (TTF)-1 (8G7G3; DakoCytomation), and a mouse monoclonal antibody against vimentin (1D2C3; DakoCytomation).

Cytological findings of the CT-guided fine-needle aspiration specimen. The Papanicolaou smear revealed the presence of two distinct neoplastic components in a necrotic background (Fig. 1A). One component was composed of small-sized neoplastic cells showing nuclear molding and loose aggregates (Fig. 1A and B). These neoplastic cells were round to oval in shape, and had scant cytoplasm and a high nuclear/cytoplasmic ratio and round to oval nuclei with finely dispersed granular nuclear chromatin and absent or inconspicuous nucleoli (Fig. 1A and B). Although apparent mitotic figures were not observed, apoptotic bodies were noted. This component was typical for SCLC. The other component was composed of loose aggregates or single discohesive giant cells (Fig. 1A-C). These cells were round to oval in shape, and had large and irregularly lobulated hyperchromatic nuclei, which were approximately 7 to 10 times larger than those of SCLC, with conspicuous single or multiple nucleoli (Fig. 1A-C). The latter component corresponded to giant cell carcinoma. No spindle cell, squamous cell carcinoma, or adenocarcinoma components were noted.

Accordingly, combined SCLC with giant cell carcinoma component was suspected.

Histopathological findings of the CT-guided needle biopsy specimen. Microscopic examination revealed proliferation of small round cells with a high nuclear/cytoplasmic ratio and scant cytoplasm. These neoplastic cells had round to oval nuclei with dispersed granular nuclear chromatin without nucleoli. Mitotic figures were easily observed. These histopathological features were typical for SCLC. No giant cell carcinoma component, which was observed in the cytological specimen, was present.

Histopathological findings of the lobectomy specimen. Histopathological study demonstrated the presence of two distinct neoplastic components (Fig. 2A). One component was SCLC (approximately $60 \%$ of the tumor), which was
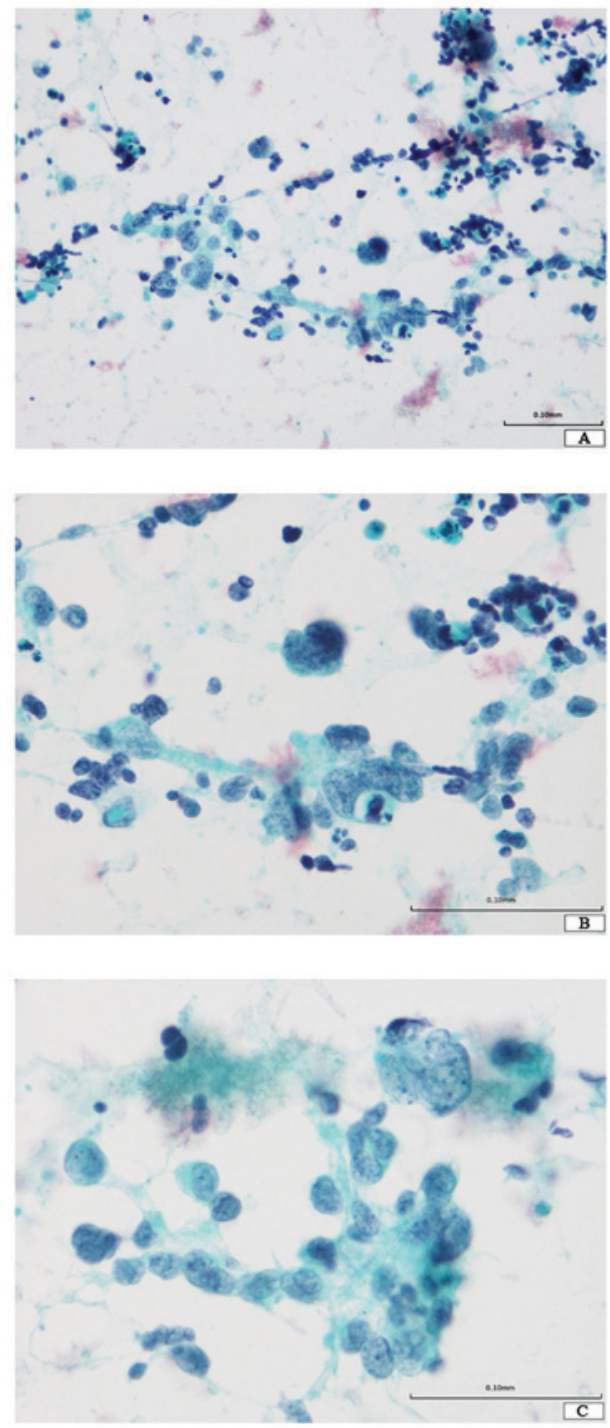

Figure 1.Cytological findings of the computed tomography-guided fine-needle cytological specimen. (A) Presence of two distinct neoplastic components in a necrotic background. One component comprises small round cells (upper), and the other component is a loose aggregates of large-sized cells (lower) (Papanicolaou stain; original magnification, x200). (B) One component is composed of small-sized neoplastic cells showing nuclear molding. These neoplastic cells have scant cytoplasm and round to oval nuclei with dispersed granular chromatin without nucleoli (top). Giant cells have large nuclei, approximately 7 times larger than those of small cell carcinoma, with coarse chromatin (Papanicolaou stain; original magnification, x400). (C) Loose aggregates of giant cells. A multinucleated giant cell with coarse chromatin is also noted (Papanicolaou stain; original magnification, $\mathrm{x} 400$ ).

composed of a sheet-like proliferation of small round cells with scant cytoplasm (Fig. 2B). These neoplastic cells had oval nuclei with dispersed granular chromatin without nucleoli (Fig. 2B). Mitotic figures and apoptotic bodies were easily observed (Fig. 2B). The other component was giant cell carcinoma (approximately $40 \%$ of the tumor) (Fig. 2A). The neoplastic cells were round to oval in shape and had relatively rich eosinophilic cytoplasm and single or multiple large nuclei with coarse chromatin (Fig. 2C). The nuclei of this component were more than 7-10 times larger than those of the SCLC cells (Fig. 2C). Mitotic figures and apoptotic bodies were easily observed. Neither differentiated carcinoma, including adenocarcinoma and squamous cell carcinoma, nor spindle cell 

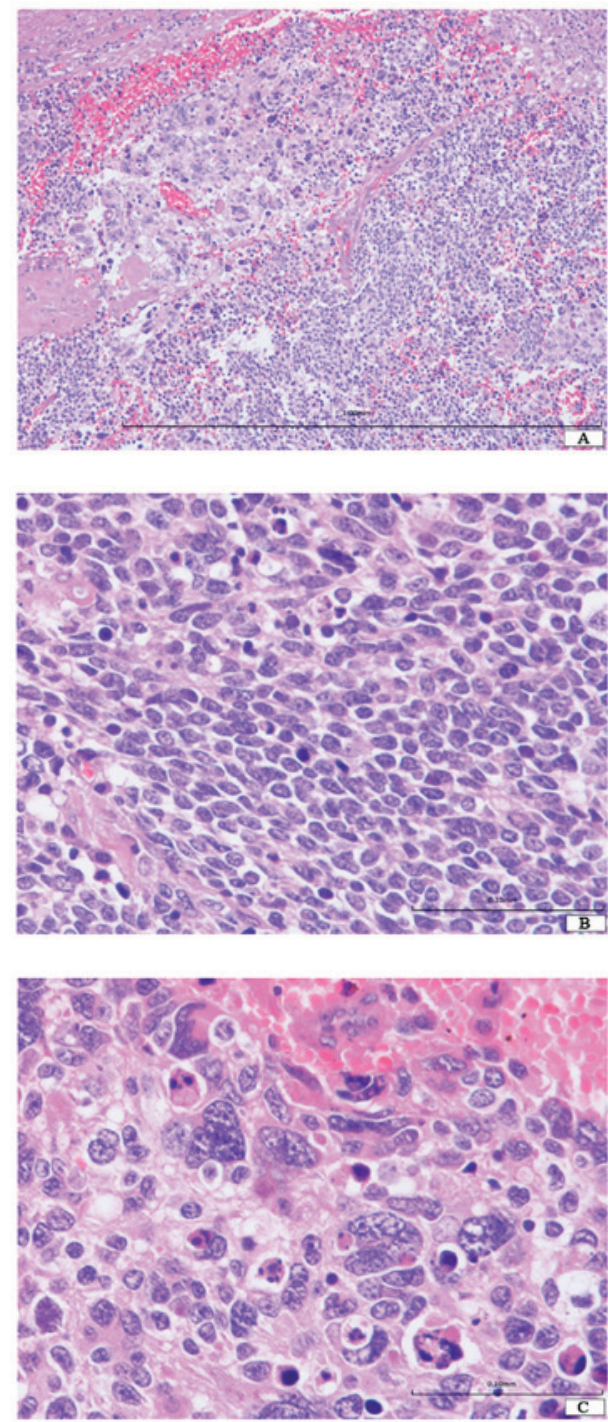

Figure 2. Histopathological features of the lobectomy specimen. (A) Two distinct neoplastic components are present. Proliferation of small-sized neoplastic cells with scant cytoplasm (right) and large-sized neoplastic cells (left) (H\&E; original magnification, x100). (B) Small cell carcinoma component. The small-sized neoplastic cells have round to oval nuclei with finely dispersed granular chromatin without nucleoli. Mitotic figures are scattered. (H\&E; original magnification, x400). (C) Giant cell carcinoma component. The neoplastic cells are large, oval to polygonal shaped, and have rich eosinophilic cytoplasm. These cells have irregular large nuclei with coarse chromatin with nucleoli (H\&E; original magnification, $\mathrm{x} 400$ ).

carcinoma component was present. Lymph node metastases (SCLC component) were observed (6/23).

Immunohistochemical findings of the lobectomy specimen. The neoplastic cells of SCLC were diffusely positive for chromogranin A, synaptophysin, and CD56 (Fig. 3A). TTF-1 and E-cadherin were also expressed. However, p40 and vimentin were not expressed (Fig. 3B and C).

The giant neoplastic cells were positive for CD56 and synaptophysin, and TTF-1 was focally expressed (Fig. 3A). Chromogranin A and $\mathrm{p} 40$ were not expressed.E-cadherin was not expressed, however, vimentin was diffusely expressed (Fig. 3B and C).

According to these results, a final diagnosis of combined SCLC with giant cell carcinoma component (pT1b N2 M0, stage IIIA) was made.
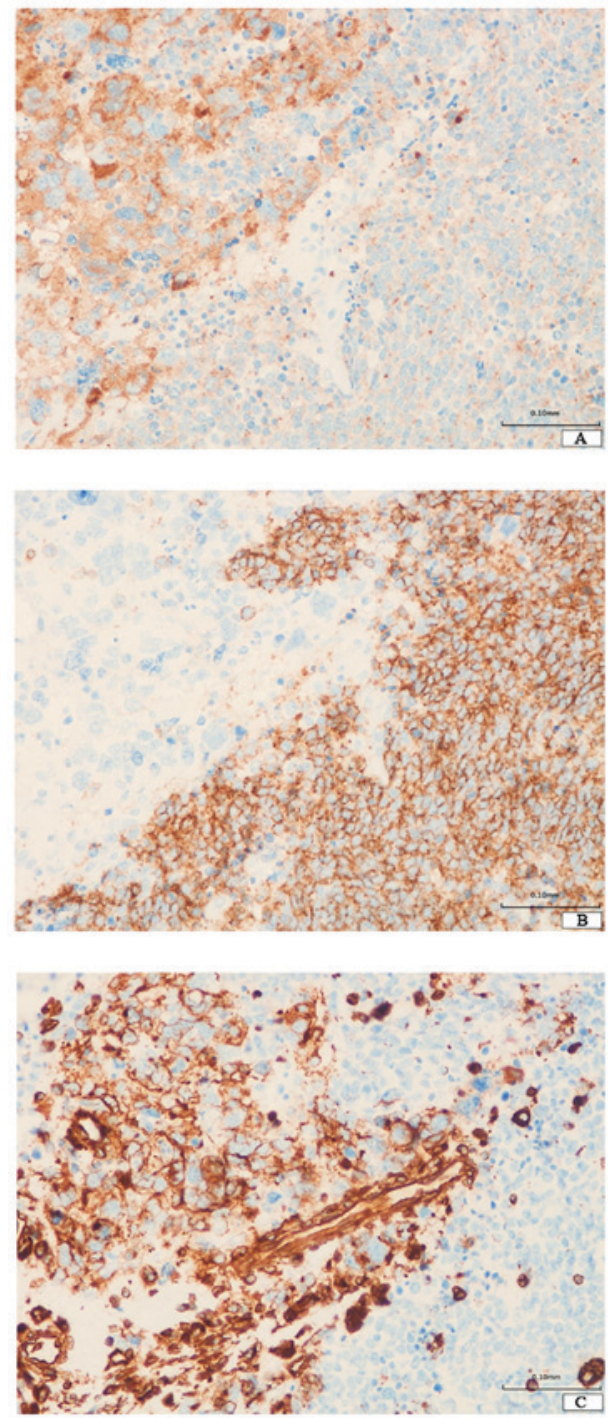

Figure 3. Immunohistochemical features of the lobectomy specimen. (A) Synaptophysin is expressed in both small cell carcinoma and giant cell carcinoma (original magnification, x200). (B) E-cadherin is expressed in small cell carcinoma, but not in giant cell carcinoma (original magnification, $\mathrm{x} 200$ ). (C) Vimentin is expressed in giant cell carcinoma, but not in small cell carcinoma (original magnification, $\mathrm{x} 200$ ).

\section{Discussion}

Herein, we describe the first reported cytological case of combined SCLC with giant cell carcinoma component. The present case carries an important message to consider in cytodiagnosis of carcinoma with neoplastic giant cell component in respiratory cytological specimens because neoplastic giant cells are occasionally observed in various types of tumors, and some neoplastic conditions-such as SCLC and giant cell carcinoma- must be included in differential diagnostic considerations.

Pleomorphic carcinoma is a relatively rare, highly aggressive histopathological variant of lung cancer, and is defined as a poorly differentiated non-SCLC that contains at least $10 \%$ neoplastic spindle and/or giant cells (11). Most pleomorphic carcinomas contain both non-SCLC and spindle cell and/or giant cell components $(11,12)$, and SCLC with giant cell carcinoma component is extremely rare. Nicholson et al reported 
Table I. The cytological features of pleomorphic carcinoma.

i) The tumor cells are arranged in monolayer, 3-dimentional clusters, or as scattered single cells in a necrotic (with or without inflammation) background.

ii) The tumor cells are large and epithelioid, spindle, or pleomorphic in shape, and show marked pleomorphism.

iii) The sizes of the tumor cells vary more than fivefold.

iv) The chromatin is unevenly distributed and there is a prominent single nucleolus; the tumor cells have abundant thick cytoplasm.

v) Mono-, bi-, and multi-nucleated giant cells can be present, and the nucleus of the giant cells are hyperchromatic to vesicular, bizarre in shape, and more than 5 times the size of the nucleus of the small lymphocytes, and often much larger.

the largest case series of combined SCLC, and non-SCLC component was present in 28 of 100 cases, but none with giant cell carcinoma (4). According to the other case series of combined SCLC, none case with giant cell carcinoma was observed (2). Moreover, Fishback et al reported that only 1 of 48 cases of giant cell carcinoma had SCLC component (13). Only a few reports regarding the cytological features of pleomorphic carcinoma have been published (14-17).

The characteristic cytological features of pleomorphic carcinoma are summarized in Table I. The cytological features of v) in Table I are characteristic for giant cell carcinoma, and the cytological features of the present case corresponded to these features.

The histopathological diagnosis of the lung tumors with giant cells may be straightforward because presence of neoplastic non-giant cell component is easily detectable. However, cytological diagnosis may be challenging because in respiratory cytological specimens, the neoplastic giant cells can be found in various types of tumors, including giant cell carcinoma, non-SCLC, and pulmonary blastoma $(18,19)$. Poorly differentiated non-SCLC occasionally contains neoplastic giant cells, however, a conventional non-giant cell carcinoma component, such as adenocarcinoma and squamous cell carcinoma, may be present in a cytological specimen. Pulmonary blastoma may have bizarre giant cells of a mesenchymal component, however, this type of rare tumor typically has sheets of cohesive epithelial cells as a glandular component (19).

Moreover, pure SCLC must be included in the differential diagnostic consideration of a lung tumor with giant cells because it is well recognized that SCLC occasionally shows cytological pleomorphism in the form of scattered or clustered multinucleated giant cells as the tumor size increases (4). Therefore, the present case must be differentiated from SCLC with giant cells. However, the current case contained abundant loose aggregates or single discohesive giant cells (the nuclear size was more than 7 to 10 times larger than those of SCLC), in contrast, scattered giant cells are typically observed in SCLC. Therefore, a cytodiagnosis of combined SCLC with giant cell carcinoma component was made.

In the present case, the giant cell carcinoma component was only present in the CT-guided fine-needle aspiration cytological specimen, but not in the needle biopsy specimen. Thus, the CT-guided fine-needle aspiration cytological examination aided the accurate pre-operative diagnosis of combined SCLC.

The giant cell carcinoma component of the present tumor was immunohistochemically positive for vimentin, but E-cadherin and p40 were not expressed. This immunohistochemical profile corresponded to that of giant cell carcinoma (11), which may suggest occurrence of epithelial-mesenchymal transition in giant cell carcinoma.

Because of rarity of combined SCLC with giant cell carcinoma component, the prognosis and therapeutic strategy for this type of tumor has not been determined. Therefore, the significance of pre-operative diagnosis of this type of tumor has not been concluded. However, accurate pre-operative diagnosis is important for further analyses, and additional studies are needed to clarify this issue.

In conclusion, we describe the first reported case of combined SCLC with giant cell carcinoma component successfully diagnosed in a CT-guided fine-needle aspiration cytological specimen. Both SCLC and giant cell carcinoma show the characteristic cytological features, therefore, albeit extremely rare, careful observation can lead to detection of giant cell carcinoma as well as SCLC in cytological specimens.

\section{References}

1. Brambilla E, Beasley MB, Austin JHM, Capellozzi VL, Chirieac LR, Devesa SS, Frank GA, Gazdar A, Ishikawa Y, et al: Small cell carcinoma. In: WHO Classification of Tumours of the Lung, Pleura, Thymus and Heart. Travis WD, Brambillia E, Burke AP, Marx A and Nicholson AG (eds). IARC, Lyon, pp63-68, 2015.

2. Yamada K, Maeshima AM, Tsuta K and Tsuda H: Combined high-grade neuroendocrine carcinoma of the lung: Clinicopathological and immunohistochemical study of 34 surgically resected cases. Pathol Int 64: 28-33, 2014.

3. Ruffini E, Rena O, Oliaro A, Filosso PL, Bongiovanni M, Arslanian A, Papalia E and Maggi G: Lung tumors with mixed histologic pattern. Clinico-pathologic characteristics and prognostic significance. Eur J Cardiothorac Surg 22: 701-707, 2002.

4. Nicholson SA, Beasley MB, Brambilla E, Hasleton PS, Colby TV, Sheppard MN, Falk R and Travis WD: Small cell lung carcinoma (SCLC): A clinicopathologic study of 100 cases with surgical specimens. Am J Surg Pathol 26: 1184-1197, 2002.

5. Zaharopoulos P, Wong JY and Stewart GD: Cytomorphology of the variants of small-cell carcinoma of the lung. Acta Cytol 26: 800-808, 1982 .

6. Tsubota YT, Kawaguchi T, Hoso T, Nishino E and Travis WD: A combined small cell and spindle cell carcinoma of the lung: Report of a unique case with immunohistochemical and ultrastructural studies. Am J Surg Pathol 16: 1108-1115, 1992.

7. Gotoh M, Yamamoto Y, Huang CL and Yokomise H: A combined small cell carcinoma of the lung containing three components: Small cell, spindle cell and squamous cell carcinoma. Eur J Cadiothorac Surg 26: 1047-1049, 2004.

8. Fujiwara M, Horiguchi M, Inage Y, Horiguchi $\mathrm{H}$, Satoh $\mathrm{H}$ and Kamma H: Combined small cell carcinoma in the peripheral lung: Importance of appropriate sampling. Acta Cytol 49: $575-578,2005$. 
9. Purkait S, Jain D, Madan K, Mathur S and Iyer VK: Combined small cell carcinoma of the lung: A case diagnosed on bronchoscopic wash cytology and bronchial biopsy. Cytopathology 26: 197-199, 2015

10. Saito T, Tsuta K, Fukumoto KJ, Matsui H, Konobu T, Torii Y, Yokoi T, Kurata T, Kurokawa H, Uemura Y, et al: Combined small cell lung carcinoma and giant cell carcinoma: A case report. Surg Case Rep 3: 52, 2017.

11. Kerr KM, Pelosi G, Austin JHM, Brambilla E, Geisinger K, Jambhekar NA, Jett J, Koss MN, Nicholson AG, et al: Pleomorphic, spindle cell and giant cell carcinoma. In: WHO Classification of Tumours of the Lung, Pleura, Thymus and Heart. Travis WD Brambillia E, Burke AP, Marx A and Nicholson AG (eds). IARC, Lyon, pp88-90, 2015.

12. Mochizuki T, Ishii G, Nagai K, Yoshida J, Nishimura M, Mizuno T, Yokose T, Suzuki K and Ochiai A: Pleomorphic carcinoma of the lung: Clinicopathologic characteristics of 70 cases Am J Surg Pathol 32: 1727-1735, 2008.

13. Fishback NF, Travis WD, Moran CA, Guinee DG Jr, McCarthy WF and Koss MN: Pleomorphic (spindle/giant cell) carcinoma of the lung. A clinicopathologic correlation of 78 cases. Cancer 73: 2936-2945, 1994.
14. Choi HS, Seol H, Heo IY, Jung CW, Cho SY, Park S, Koh JS and Lee SS: Fine-needle aspiration cytology of pleomorphic carcinomas of the lung. Korean J Pathol 46: 576-582, 2012.

15. Zafar N and Johns CD: Pleomorphic (sarcomatoid) carcinoma of lung-cytohistologic and immunohistochemical features. Diagn Cytopathol 39: 115-116, 2011.

16. Hiroshima K, Dosaka-Akita H, Usuda K, Ogura S, Kusunoki Y, Kodama T, Saito Y, Sato M, Tagawa Y, Baba M, et al: Cytological characteristics of pulmonary pleomorphic and giant cell carcinomas. Acta Cytol 55: 173-179, 2011.

17. Hummel P, Cangiarella JF, Cohen JM, Yang G, Waisman J and Chhieng DC: Transthoracic fine-needle aspiration biopsy of pulmonary spindle cell and mesenchymal lesions: A study of 61 cases. Cancer 93: 187-198, 2001.

18. Alasio TM, Sun W and Yang GC: Giant cell carcinoma of the lung impact of diagnosis and review of cytological features. Diagn Cytopathol 35: 555-559, 2007.

19. Mahon BM, Placido JB and Gattuso P: Fine-needle aspiration of classic biphasic pulmonary blastoma. Diagn Cytopathol 38: 427-429, 2010. 